\title{
The Four types of Tregs in malignant lymphomas
}

\author{
Jing Wang and Xiao-Yan Ke*
}

\begin{abstract}
Regulatory $T$ cells (Tregs) are a specialized subpopulation of $C D 4^{+} T$ cells, which act to suppress the activation of other immune cells. Tregs represent important modulators for the interaction between lymphomas and host microenvironment. Lymphomas are a group of serious and frequently fatal malignant diseases of lymphocytes. Recent studies revealed that some lymphoma T cells might adopt a Treg profile. Assessment of Treg phenotypes and genotypes in patients may offer prediction of outcome in many types of lymphomas including diffuse large Bcell lymphoma, follicular lymphoma, cutaneous T cell lymphoma, and Hodgkin's lymphoma. Based on characterized roles of Tregs in lymphomas, we can categorize the various roles into four groups: (a) suppressor Tregs; (b) malignant Tregs; (c) direct tumor-killing Tregs; and (d) incompetent Tregs. The classification into four groups is significant in predicting prognosis and designing Tregs-based immunotherapies for treating lymphomas. In patients with lymphomas where Tregs serve either as suppressor Tregs or malignant Tregs, anti-tumor cytotoxicity is suppressed thus decreased numbers of Tregs are associated with a good prognosis. In contrast, in patients with lymphomas where Tregs serve as tumor-killing Tregs and incompetent Tregs, anti-tumor cytotoxicity is enhanced or anti-autoimmune Tregs activities are weakened thus increased numbers of Tregs are associated with a good prognosis and reduced numbers of Tregs are associated with a poor prognosis. However, the mechanisms underlying the various roles of Tregs in patients with lymphomas remain unknown. Therefore, further research is needed in this regard as well as the utility of Tregs as prognostic factors and therapy strategies in different lymphomas.
\end{abstract}

Keywords: lymphomas, regulator T cells, prognosis

\section{Introduction}

$\mathrm{CD} 4{ }^{+} \mathrm{CD} 25^{\text {high }} \mathrm{FOXP} 3+$ Regulatory $\mathrm{T}$ cells (Tregs) are a specialized subpopulation of $\mathrm{CD} 4^{+} \mathrm{T}$ cells, which act to suppress the activation of other immune cells, maintains the immune system homeostasis, and suppresses effector $\mathrm{T}$ cells in the periphery and control excessive response to foreign antigens [1]. Several Treg subsets have been identified and extensively studied. Naturally occurring Tregs represent approximately $5 \%$ to $10 \%$ of peripheral $\mathrm{CD} 4^{+} \mathrm{T}$ cells in both mice and humans [2-4]. Besides naturally occurring Tregs, there are also adaptively induced antigen-specific Tregs. These cells exist in markedly higher proportions within tumor-infiltrating lymphocytes, peripheral blood lymphocytes, and/or regional lymph node lymphocytes. It has been widely acknowledged that tumor-related immunosuppression plays an important role in determining both the severity

\footnotetext{
* Correspondence: xiaoyank@yahoo.com

Department of Hematology and Lymphoma Research Center, Peking University, Third Hospital, (Huayuan North Road 49\#), Beijing (100191), PR China
}

(C) 2011 Wang and Ke; licensee BioMed Central Ltd. This is an Open Access article distributed under the terms of the Creative Commons Attribution License (http://creativecommons.org/licenses/by/2.0), which permits unrestricted use, distribution, and reproduction in any medium, provided the original work is properly cited. of disease and the responsiveness to therapy [5-7]. Tumor-specific Tregs require ligand-specific activation and cell-to-cell contact to exert their suppressive activity on tumor-specific effector $\mathrm{T}$ cells, which includes decreased cytotoxity, proliferation, and type $1 \mathrm{~T}$ helper cell (Th1) cytokine secretion. Through variable mechanisms, Tregs inhibit many adaptive and innate immune cells, including $\mathrm{CD} 4^{+} \mathrm{T}$ cells, $\mathrm{CD} 8^{+} \mathrm{T}$ cells, dendritic cells, macrophages, and $B$ cells [8]. In recent years, it has been shown that Tregs also inhibit NK cells in a transforming growth factor- $\beta$ (TGF- $\beta$ )-dependent manner [9-11]. In some tumors, high numbers of Tregs are associated with a poor prognosis due to the fact that the presence of Tregs in the tumor microenvironment diminishes anti-tumor immune responses. These results might explain why current clinical trials using cancer peptides or dendritic cells (DCs) pulsed with antigenic peptides induce only transient immune responses and fail to produce therapeutic benefits [12-14].

Tregs represent important modulators for the interaction between lymphomas and the host 
microenvironment. Depletion or blockade of Tregs can enhance immune protection responses elicited by tumor-associated self-antigens. Lymphomas are a group of serious and frequently fatal malignant diseases of lymphocytes. Lymphomas are variable in their clinical features. Despite significant progress, the molecular and cellular mechanisms underlying the clinical aspects of lymphomas are largely unknown [15]. Recent studies revealed that some lymphoma $\mathrm{T}$ cells might adopt a Treg profile as well [16]. Assessment of Treg phenotypes and genotypes in patients may offer prediction of outcome in many types of lymphomas including diffuse large B-cell lymphoma (DLBCL), follicular lymphoma (FL), cutaneous $\mathrm{T}$ cell lymphoma (CTCL), and Hodgkin's lymphoma. Recent reports have shown that the presence of increased numbers of activated intratumoral $\mathrm{CD}_{4}^{+} \mathrm{T}$ cells predicts a better overall survival rate in patients with lymphoma [17]. But further research is needed to clarify the complex status of Tregs in malignant lymphomas. Based on Tregs' roles characterized in lymphomas, we can categorize various roles of Tregs into four groups: (a) Suppressor Tregs: Tregs' suppression of anti-tumor $\mathrm{CD}^{+} \mathrm{T}$ cell-mediated immune responses is observed in various lymphomas, which is similar to the ones found in solid tumors, carcinomas, and myeloid malignancies [18]; (b) Malignant Tregs: FOXP3 is a selective marker for a subset of adult $\mathrm{T}$ cell leukemia/lymphoma (ATLL) and cutaneous T-cell lymphomas (CTCL) suggesting that Tregs can be malignant $[19,20]$; (c) Direct tumor-killing Tregs: Some B cell lymphoma cells can be target cells for Tregs suppressive cytotoxicity suggesting that Tregs are tumor cell killers [21,22]; and (d) Incompetent Tregs: a reduced infiltration of Tregs, which are mostly rTreg in angioimmunoblastic T-Cell lymphoma (AITL), potentially contributing to the autoimmune symptoms, suggesting that rTregs in patients with AITL are incompetent Tregs [23] as indicated by our new working model (Figure 1). Our new classification of Tregs into four groups is significant in providing an insight into the effects of Tregshost microenvironment interaction on Tregs' function. In addition, our new classification also predicts prognosis of these diseases and can be very useful in designing Tregs-based immunotherapies for treating lymphomas in the future. For example, in the patients with lymphomas where Tregs serve as either suppressor Tregs or malignant Tregs, anti-tumor cytotoxicity is suppressed thus decreased numbers of Tregs are associated with a good prognosis. In contrast, patients with lymphomas where Tregs serve as tumor-killing Tregs and incompetent Tregs, anti-tumor cytotoxicity is enhanced or anti-autoimmune Tregs activities are weakened thus increased numbers of Tregs are associated with a good prognosis and reduced numbers of Tregs are associated with a poor prognosis.

\section{Non-Hodgkin's Lymphoma}

Non-Hodgkin's lymphoma (NHL) is a diverse group of lymphoid malignancies, which currently remains incurable. NHL accounts for about $90 \%$ of lymphoid neoplasms. Accumulating evidence shows that Tregs are highly concentrated in tumors, thereby fostering an immune-privileged microenvironment. Thus, newly diagnosed NHL patients are in an immunosuppressive state. Peripheral blood Tregs levels are irrelevant to the status of disease [24]. Patients with unhealthy habits

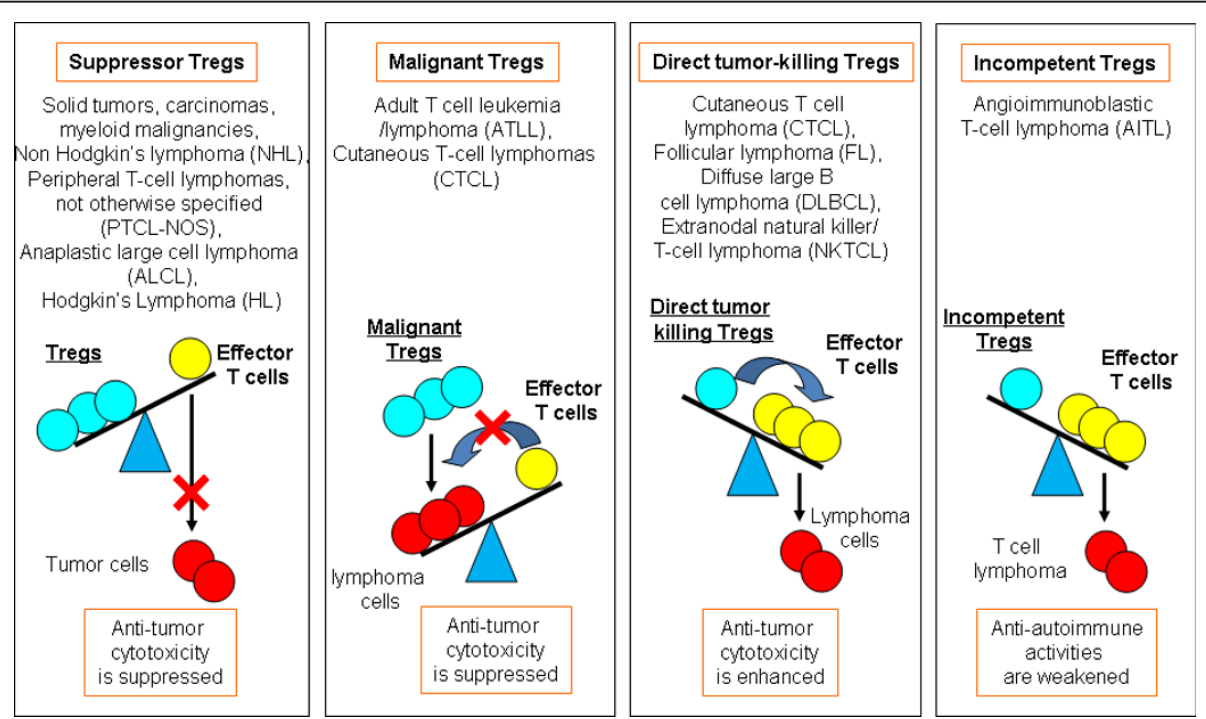

Figure 1 Figure Four types of Tregs' functions have been identified in patients with lymphomas. 
(smoking, alcohol abuse) have higher peripheral blood Tregs levels. CD $4^{+} \mathrm{CD} 25^{+} \mathrm{FOXP}^{+} \mathrm{CD} 127^{\text {low }}$ Tregs are markedly increased in peripheral blood mononuclear cells (PBMCs) versus healthy controls regardless of lymphoma subtype, and correlated with disease stage and serum lactate dehydrogenase. A high proportion of Tregs are also present in involved tissues versus reactive nodes. Thus, NHL cells are powerful inducers of Tregs, which may represent a new therapeutic target [25]. $\mathrm{FOXP}^{+}$Treg density is varied in different lymphoma types and is highest in follicular lymphoma.

Lymphoma-infiltrating FOXP3 ${ }^{+}$cells may represent important lymphoma/host microenvironment-modulators, since increased number of these cells can positively influence survival in FL, germinal center (GC)-like DLCBL. In a Cox regression model, considering clinical stages and age, the numbers of FOXP3+ Tregs are of independent prognostic significance for disease-specific survival in GC-like DLBCL. In contrast, Tregs have a negative prognostic effect in non-GC-like DLBCL. The reason for these discrepancies remains unclear, although the expression of FOXP3 ${ }^{+}$by activated Th1 cells may provide an explanation [19]. Lee et al indicated that an increased percentage of FOXP3-positive Tregs in DLBCL is predictive of better prognoses. As compared with the others, patients with higher percentages of FOXP3-positive Tregs on initial tumor biopsy have a significantly longer OS $(p=0.003)$. When the prognostic factors are evaluated via a multivariate model, the international prognostic index and the percentages of infiltrating FOXP3-positive Tregs in the initial biopsy are identified as independent predictors of OS [20].

Yang et al [26] demonstrated in NHL Tregs attenuated CD8 T-cell function, thereby protecting lymphoma cells from cytotoxic activity. Likewise, Hilchey et al [27] demonstrated that follicular lymphoma intratumoral Tregs suppressed CD3/CD28-costimulated autologous and allogenic $\mathrm{CD} 8^{+} \mathrm{CD} 25^{-}$and $\mathrm{CD} 4^{+} \mathrm{CD} 25^{-}$effector $\mathrm{T}$ cells. Tregs and mast cells (MCs) are involved in immunosuppression in B-cell NHL and IL-9 is a key mediator of Tregs and MCs [28]. These might provide novel insight for the pathogenesis and possible therapeutic strategy of B-cell NHL. T-cell hyporesponsiveness is reversed by depleting $\mathrm{CD} 25^{+}$cells or by adding antiCTLA-4, supporting the view that Tregs explain the systemic immunosuppression seen in NHL. Interestingly, a high level of soluble CD25 (sCD25) has been associated with a poor prognosis in patients with NHL. The function and origin of this soluble receptor are not well investigated. Tregs may release CD25 to act as a decoy receptor for IL-2, thereby depriving T-effector cells of growth factor IL-2 [29]. Thus, in patients of different types of NHL, the percentage and the function of tumor-infiltrating FOXP3+ $\mathrm{T}$ cells predicts different survival. Further research is needed in the utility of Tregs as prognostic factors and therapy strategies.

\section{Follicular Lymphoma}

Follicular lymphoma (FL) is the second most common subtype of adult B-cell NHL in Western countries and is characterized by the chromosome translocation $\mathrm{t}$ $(14 ; 18)$. This abnormality promotes tumor cell survival through overexpression of the anti-apoptotic protein $\mathrm{Bcl}-2$. Of interest, mice overexpressing $\mathrm{Bcl}-2$ under the control of the immunoglobulin enhancer develop follicular hyperplasia rather than FL, indicating that pathogenetic mechanisms other than $\mathrm{Bcl}-2$ over expression exist in FL [30]. In contrast to other B-cell lymphomas where gene expression in the malignant B-cell population determines survival, the composition of the lymphoma microenvironment at diagnosis seems to determine the survival of patients with FL [31]. Some studies have shown that stimulation of the $\mathrm{T}$ cell antigen receptor (TCR) or priming with dendritic cells can induce FOXP3 expression and the acquisition of Tregs activity in $\mathrm{CD} 4^{+} \mathrm{CD} 25^{-} \mathrm{T}$ cells from normal PBMC [32-34]. Yang et al [35] extended these findings and demonstrated that tumor infiltrating $\mathrm{T}$ cells in FLinvolved lymph nodes could also be induced to express FOXP3 through TCR stimulation. Furthermore, they showed that $\mathrm{CD} 70^{+}$malignant $\mathrm{B}$ cells could facilitate this conversion of conventional $\mathrm{T}$ cells to Tregs in FL. Ai et al found that tumor B cells alone, without artificial TCR stimulation, could induce conventional $\mathrm{T}$ cells to express FOXP3 and acquire regulatory function. In contrast to their malignant counterpart, normal B cells did not induce Tregs conversion. Tregs conversion is independent of the $\mathrm{T}$ cell background, as $\mathrm{T}$ cells isolated from FL or normal peripheral blood are equally susceptible to being converted by tumor B cells. There is a tumor-specific mechanism by which FL tumor cells promote immune escape through the induction of Tregs [36].

In a study where Tregs are detected in FL patients, the median Tregs percentage at diagnosis is $10.5 \%$. Overall, 49 patients have more than $10 \%$ Tregs, 30 have between $5 \%$ to $10 \%$, and 19 have less than $5 \%$, with a 5 -year OS of $80 \%, 74 \%$, and $50 \%$, respectively $(p=0.001)$. Patients with very low numbers of Tregs $(<5 \%)$ are associated with high frequencies for refractory disease $(p=0.007)$. The prognostic significance of Tregs numbers is independent of the FL International Prognostic Index (FLIPI). Seven transformed diffuse large B-cell lymphomas (DLBCLs) have lower Tregs percentages (mean: $3.3 \%$ ) than FL grades 1,2 (mean: $12.1 \%$ ) or 3 (mean: $9 \%$ ) $(p<0.02)$. These results demonstrate that the number of tumor-infiltrating FOXP3-positive Tregs is a predictor of survival in patients with FL; high Treg numbers 
predict improved survival and the number of these cells decreases during the transformation to DLBCL. Tregs may be an important subset of cells in the tumor microenvironment modulating the host immune response and biologic behavior of FL [37]. In conclusion, FL tumor cells can promote immune escape through the induction of Tregs, whereas Tregs also can serve as direct tumorkilling Tregs in FL.

\section{Adult T-cell leukemia/lymphoma}

Adult T-cell leukemia/lymphoma (ATLL) is an aggressive lymphoma associated with human T-lymphotrophic virus 1 (HTLV1) infection, and ATLL cells frequently express several molecules that are characteristic of Tregs, notably CD4, CD25, and the transcription factor FOXP3. However, this phenotype is not characteristically found in other lymphomas [38]. Therefore it has been recently suggested that HTLV-1 selectively infects and transforms Tregs [39]. It is expected that HTLV-1 infected cells should be recognized and eradicated by HTLV-1-specific cytotoxic T lymphocytes (CTLs). However, HTLV-1 specific CTLs are suppressed by Treg activities. The reason is that HTLV-1 infected Tregs may have a survival advantage compared to other types of cells by suppressing host immune responses against themselves. As a result, HTLV-1 infected CD $4{ }^{+}$CD 25 ${ }^{+}$CCR $4{ }^{+}$Tregs should preferentially survive, and gradually increase in numbers. Furthermore, the accumulation of additional crucial genomic and/or epigenomic alterations could cause HTLV-1 infected cells to change into clonally proliferating ATLL cells.

Bangham et al showed that HTLV-1 induces and maintains a high frequency of $\mathrm{FOXP}^{+} \mathrm{T}$ cells by inducing expression of the chemokine CCL22; the frequency is especially high in patients with chronic ATLL. In turn, the FOXP3 ${ }^{+} \mathrm{T}$ cells exert both potentially beneficial and harmful effects: they may suppress the growth of autologous ATLL clones and also may suppress the host's cytotoxic $\mathrm{T}$ lymphocyte response, which normally limits HTLV-1 replication and reduces the risk of HTLV-1 infection-associated diseases. Although ATLL cells may exert immune suppressive effects, ATLL is not necessarily a tumor of classical FOXP3 ${ }^{+}$Tregs [40]. Thus, Tregs in ATLL partly serve as malignant Tregs and lead to progress of the disease.

\section{Cutaneous T-Cell Lymphoma}

Cutaneous T-cell lymphomas (CTCLs) are non-Hodgkin's lymphomas derived from $\mathrm{T}$ cells that home to and inhabit the normal function and structure of skin. There are conflicting reports as to whether CTCLs represent a malignancy of Tregs. Sézary syndrome (SS) is an aggressive variant of cutaneous T-cell lymphoma. Heid et al. presented convincing evidence that the malignant $\mathrm{T}$ cells in a subgroup of Sézary patients are FOXP3 ${ }^{+}$ Tregs. Clonal malignant $\mathrm{T}$ cells show increased expression of the Treg-associated transcription factor FOXP3 and demethylation of the foxp3 gene locus, and $\mathrm{T}$ cells from some of these patients suppressed T-cell proliferation in vitro [41]. Mycosis fungoides (MF) with early or infiltrated plaques have significantly higher numbers of FOXP3+ Tregs than CTCL unspecified or advanced MF with tumors or transformation to large cell lymphoma. An analysis of CTCL patients demonstrated that increased numbers of FOXP3+ Tregs are associated with improved survival in both MF and CTCL unspecified [42]. Knol et al. showed that functional circulating $\mathrm{CD} 4{ }^{+} \mathrm{CD} 25^{\text {high }} \mathrm{FOXP}^{+}$regulatory $\mathrm{T}$-cells in CTCL patients are increased compared to that in healthy donors [43]. FOXP3-positive $\mathrm{T}$ cells occur in higher proportions in the dermis than in the epidermis and probably correlate with coexisting inflammatory components [44].

In addition to that discussed above, others have contrary opinions. Some studies showed that CTCL neoplastic cells do not typically express a Tregs phenotype and are associated with low numbers of FOXP3-positive Tregs in the infiltrate. FOXP3-positive T cells are less frequently encountered in MF than in inflammatory dermatoses. In eight of 15 (53\%) Sézary patients, significantly reduced percentages of $\mathrm{FOXP}^{+}$cells are seen in blood (2.9\%) and skin (10.4\%). Interestingly, six of 15 (40\%) Sézary patients show significantly increased percentages of FOXP3 ${ }^{+}$cells $(39.7 \%$ (blood), 20.3\% (skin)); however, these cells do not express CD25. In these latter patients, clone-specific TCR-V $\beta$-chain antibodies were used to demonstrate that these FOXP3 ${ }^{+} \mathrm{CD} 25^{-}$cells are monoclonal CTCL tumor cells. FOXP3+CD25- CTCL tumor cells show a highly demethylated status of the Foxp3 gene locus similar to Tregs, and they are functionally able to suppress IL-2 mRNA induction in TCR-stimulated conventional $\mathrm{T}$ cells. Thus, FOXP $3^{+} \mathrm{CD} 25^{-} \mathrm{CTCL}$ tumor cells with functional features of Tregs define a subgroup of Sézary patients who might carry a different prognosis and might require different treatments [45].

In an extracorporeal photopheresis (ECP) treatment group, the baseline of circulating $\mathrm{CD} 4{ }^{+} \mathrm{CD} 25^{\text {tbright }}$ percentages in CTCL (median: 4.3 percent) are similar to those of healthy donors in a study. During ECP treatment, CTCL patients are characterized by an early decrease of $\mathrm{CD} 4{ }^{+} \mathrm{CD} 25^{\text {bright }}$ (from 4.3 percent to 2.4 percent median after 6 months). The CD $4^{+} \mathrm{CD} 25^{\text {tbright }}$ decrease is associated to the disease course, as it occurs in 91.3 percent of patients responding to treatment but in only 25 percent of progress disease (PD) patients ( $p=$ 0.0001). ECP induces downregulation of circulating CD4 ${ }^{+} \mathrm{CD} 25^{\text {tbright }}$ cells in CTCL is potentially associated with response mechanisms [46]. 
Tiemessen et al. found a dysfunction of peripheral Tregs in certain CTCL patients, which correlates with tumor burden. The percentages of Tregs do not differ significantly between patients and controls. Functional assays demonstrates a dichotomy in Tregs function: in four out of 10 patients, $\mathrm{CD} 4{ }^{+} \mathrm{CD} 25^{+} \mathrm{T}$ cells are incapable of suppressing autologous $\mathrm{CD} 4^{+} \mathrm{CD} 25^{-} \mathrm{T}$-cell proliferation, whereas suppressive function is intact in the other six patients. Suppressive activity of Tregs inversely correlates with the peripheral blood tumor burden. Mixed lymphocyte reactions demonstrate that CD4 ${ }^{+}$CD25- $\mathrm{T}$ cells from patients who lack functional Tregs are susceptible to suppression by Tregs from healthy controls, and have not become suppressive cells. Furthermore, expression of FOXP3 is reduced in the $\mathrm{CD} 4{ }^{+} \mathrm{CD} 25^{+}$Tregs of these patients compared to the other six CTCL patients and controls [47].

Immunodeficiency develops during Sézary syndrome (SS) progression. Krejsgaard et al. studied Tregs function and the expression of FOXP3 in SS. Eight of 15 patients stain positive with an anti-FOXP3 antibody in malignant $\mathrm{T}$ cells. Western blotting analysis shows expression of two low molecular splice forms of FOXP3, but not of wild-type (WT) FOXP3. Malignant T cells produce interleukin-10 and transforming growth factor$\beta$ (TGF- $\beta$ ) and suppress the growth of non-malignant $\mathrm{T}$ cells. The Tregs phenotype and the production of suppressive cytokines are driven by aberrant activation of Jak3 independent of the FOXP3 alternatively spliced forms. In contrast to WT FOXP3, the low molecular splice forms of FOXP3 have no inhibitory effect on nuclear factor $-\kappa \mathrm{B}(\mathrm{NF}-\kappa \mathrm{B})$ activity in reporter assays, which is in keeping with a constitutive NF- $\kappa \mathrm{B}$ activity in malignant $\mathrm{T}$ cells. Thus, malignant $\mathrm{T}$ cells express low molecular splice forms of FOXP3 and function as Tregs. Furthermore, FOXP3 splice forms are functionally different from WT FOXP3 and are not involved in the execution of the suppressive function [48]. In conclusion, the percentage and function of tumor-infiltrating $\mathrm{FOXP3}^{+} \mathrm{T}$ cells predicts different survival. Tregs in CTCLs serve as both malignant Tregs and direct tumorkilling Tregs.

\section{Extranodal natural killer/T-cell lymphoma}

Extranodal natural killer/T-cell lymphoma (NKTCL) usually derives from natural killer (NK) cells or, rarely, from cytotoxic T cells. NKTCL is common in East Asians and Mexicans, but rare in Western populations [49]. NKTCL is often refractory to radio- or chemotherapy and shows aggressive behaviors with poor clinical outcomes. Therefore, risk stratification of NKTCL is important for the appropriate management of affected patients. However, the role of alleged risk factors of non-Hodgkin's lymphoma creates limitations in evaluating the prognosis of NKTCL patients. Clinical heterogeneity and the controversial issues on the prognostic factors impose requirements for a new approach to dealing with NKTCL.

Studies show that the percentage of $\mathrm{FOXP}^{+}$subset from PBMCs in extranodal NK/T cell lymphoma (ENKTL) patients is significantly higher than that of healthy individuals $(p<0.001)$. The FOXP3 ${ }^{+}$subset from PBMCs expressed CD45RO, CTLA4, GITR, CCR7, and had an IL- $10^{\text {high }}$ IFN- $\gamma+$ TGF- $\beta+$ IL- $2^{\text {low }}$ IL- $17^{\text {low }}$ cytokine secreting phenotype. Interestingly, the existence of EBV antigen-specific $\mathrm{CD}^{+} \mathrm{FOXP}^{+}$Tregs is discovered in ENKTL. Furthermore, the high density of $\mathrm{FOXP}^{+}$tumor infiltrated lymphocytes (TILs) is associated with improved progression-free survival (PFS) in ENKTL patients $(p<0.05)$ [50]. Kim et al. also found that NK/T cell lymphoma (NKTCL) patients with increased numbers of Tregs $\left(>\right.$ or $=50 / 0.40 \mathrm{~mm}^{2}$ ) show prolonged overall and progression-free survival. In their study, tumor-infiltrating $\mathrm{FOXP3}^{+}$Tregs are much rarer in non-upper aerodigestive tract (UAT)-NKTCLs than in UAT-NKTCLs and in patients with poor performance status (PS), which might lead to poor clinical outcome of patients with decreased Tregs. However, in multivariate analysis, a paucity of Tregs is independently associated with poor clinical outcome of NKTCL patients regardless of the primary site involved and the PS. Furthermore, the quantity of Tregs has an independent prognostic value in analyses confined to UAT- or nasal NKTCLs. Therefore, it is possible that Tregs might infiltrate the NKTCL in a different manner depending on the site involved, but still have prognostic value irrespective of primary tumor site. Moreover, the independent prognostic implication of the quantity of Tregs is consistently observed in analyses of NKTCL patients treated with homogeneous modality. These observations suggest that infiltration of $\mathrm{FOXP}^{+}$Tregs in the tumor microenvironment might reflect a unique and clinically important biological aspect of NKTCL [51]. In NKTCL, Tregs might serve as direct tumor-killing Tregs.

\section{Peripheral T-cell Lymphoma, not otherwise specified}

Peripheral T-cell lymphomas, not otherwise specified (PTCL-NOS), are biologically heterogeneous and have not been successfully correlated with specific T-cell subsets. Bonzheim et al. found that one PTCL-NOS case strongly expresses FOXP3 in the neoplastic $\mathrm{T}$ cells and shows unusual histomorphologic features with a dense infiltration of the lymph node by immunoblastic $\mathrm{T}$ cells and with almost no reactive background infiltrate. The patient died shortly after diagnosis. Although the majority of patients with PTCL-NOS have a poor clinical outcome, the rapid and fatal progression seen in the 
FOXP3+ case differs from the typical clinical course of PTCL-NOS in general. Thus, FOXP3-expression and the associated regulatory phenotype might be an adverse biologic and clinical factor in rare PTCL cases that contributes to the aggressiveness of the tumor. All remaining PTCL-NOS cases show FOXP3 positivity only in the reactive infiltrate. FOXP3+ PTCL-NOS presumably derived from bona fide Tregs occurs but is rare in the Western population [52]. Like solid tumors, carcinomas, and some type of NHL, Tregs in PTCL-NOS might serve as suppressor Tregs and the anti-tumor cytotoxicity of effector $\mathrm{T}$ cells is suppressed in this disease.

\section{Angioimmunoblastic T-cell Lymphoma}

Angioimmunoblastic T-cell lymphoma (AITL) is one of the nodal $\mathrm{T}$-cell lymphomas and is characterized by lymphadenopathy, B-symptoms, and an aggressive behavior. Its natural history has been the subject of controversy, having been considered for many years to be nonmalignant disorders or dysimmune diseases. CD4 ${ }^{+} \mathrm{CD} 25^{\text {high }} \mathrm{FOXP} 3^{+} \mathrm{CD} 127^{\text {low }}$ Tregs in the tumor microenvironment play an important role in lymphoma growth regulation. Numbers of Tregs are significantly decreased in AITL lymph nodes compared with follicular lymphoma and reactive lymph nodes. Moreover, the few Tregs in lymph nodes of AITL are resting Tregs (rTregs) and have a naive CD45RA ${ }^{+}, \mathrm{PD}^{-}$, and $\mathrm{ICOS}^{-}$ phenotype, in contrast to the Tregs in follicular lymphomas or reactive lymph nodes [53]. This phenotype may potentially contributes to the autoimmune symptoms, as described in systemic lupus [54] and could participate in the poor prognosis of AITL. Interestingly, Tregs depletion is not observed in AITL peripheral blood at diagnosis. These data suggest that Tregs depletion could contribute to the nodal neoplastic $\mathrm{T}(\mathrm{FH})$ expansion and dysimmune symptoms in AITL. However, the cause of this Tregs depletion and the mechanisms of interaction between AITL neoplastic T-cells and Tregs remain to be defined. PD1 is known to be expressed by the AITL neoplastic T-cells and is also involved in the Tregs negative regulation. It is possible that the PD1 pathway is involved in down-regulation of the Tregs population observed in AITL [55]. This result indicated that rTregs in AITL are incompetent Tregs; anti-autoimmune Tregs activities are weakened and reduced numbers of Tregs are associated with a poor prognosis.

\section{Anaplastic Large Cell Lymphoma}

Primary cutaneous CD30+ lymphoproliferative disorders (LPDs) are the second most common group of cutaneous $\mathrm{T}$-cell lymphomas (CTCLs), accounting for approximately $30 \%$ of CTCLs. This group includes primary cutaneous anaplastic large cell lymphoma (CALCL), lymphomatoid papulosis (LyP), and borderline cases. It is now generally accepted that C-ALCL and LyP form a spectrum of disease, and that histologic criteria alone are often insufficient to differentiate between these two ends of this spectrum. FOXP3 expression in cutaneous and systemic $\mathrm{CD} 30^{+}$lymphoproliferations is generally confined to tumor infiltrating Tregs. These cells may have influence upon the clinical behavior, possibly depending upon the net degree of Tregs mediated immune suppression of tumor cells relative to tumor infiltrating, cytotoxic effector cells, thereby implicating the more favorable outcome of LyP compared to CALCL [56]. Only a subset of tumor cells in anaplastic lymphoma kinase (ALK)+ ALCL expresses FOXP3, and the level of expression varies among tumor cells, pointing to an intricate mechanism of FOXP3 regulation. Recent data suggest that FOXP3 may be up-regulated as a consequence of ALK deregulation in ALCL, as it has been shown in ALK+ ALCL cell lines. Kasprzycka et al. [57] demonstrated elevated FOXP3 expression in ALK+ ALCL cell lines. When transfected with nucleophosminanaplastic lymphoma kinase (NPM/ALK), the lymphoid cells can be induced to express Tregs phenotype. Inhibition of NPM/ALK function in ALK+ cell can suppress Tregs phenotype. Furthermore, NPM/ALK induced Tregs phenotype by activating its key effector, signal transducers, and activators of transcription protein 3 (STAT3) to activate interleukin-10 (IL-10), transforming growth factor $\beta$, and FOXP3 expression. These findings identified a function for NPM/ALK as an inducer of evasion of the immune response. Advanced research is needed to explore the Tregs in ALCL. Tregs may serve as the suppressor Tregs in ALCL and suppress the antitumor immune response induced by effector $\mathrm{T}$ cells.

\section{Hodgkin's Lymphoma}

Hodgkin's lymphoma (HL) is characterized by the presence of a small number of tumor cells in a rich background of inflammatory cells, but the contribution of the abundant non-tumor cells to HL pathogenesis is poorly understood. Migratory $\mathrm{CD} 4^{+}$cells induced by $\mathrm{HL}$ cells are hyporesponsive to $\mathrm{T}$-cell receptor stimulation and suppress the activation/proliferation of the effector $\mathrm{CD} 4^{+} \mathrm{T}$ cells in an autologous setting. HL cells in affected lymph nodes are surrounded by a large number of lymphocytes expressing both CC chemokine receptor 4 (CCR4) and FOXP3 [58]. The functional role of these TILs is still controversial. While generally considered to represent an anti-tumor immune response, TIL in classical HL (cHL) might result from the profoundly deregulated immunity of cHL patients.

Kelley et al. studied the prognostic importance of tumor-infiltrating regulatory $\mathrm{T}$ lymphocytes (Tregs) and cytotoxic T/NK lymphocytes (CTLs) in 98 diagnostic biopsy specimens from patients with cHL. When prior 
available MAL and bcl-2 expression data are included in a multivariate analysis of all clinical and biologic factors, a FOXP3/GrB ratio of 1 or less and tumor cell expression of MAL and bcl-2 all independently predicted poor failure-free survival (FFS) [59]. Tumor-infiltrating CTLs, T helper 1 (Th1) cells, T helper 2 (Th2) cells, and Tregs are detected to evaluate the prognostical significance. The results show that in cHL, the microenvironment is dominated by Th2 cells and Tregs; large numbers of Th2 cells are associated with significantly improved disease-free survival $(p=0.021)$ and event-free survival ( $p$ $=0.012$ ). Furthermore, a high ratio of Tregs over Th2 cells results in a significantly shortened disease-free survival $(p=0.025)$. These observations suggest that Tregs may exert inhibitory effects on anti-tumor immune responses mediated through Th2 cells and that Th2 cells may be more important for effective anti-tumor immunity than anticipated [60]. Furthermore, an increased number of Tregs in HL is associated with the loss of EBV-specific immunity. Baumforth et al. found that in EBV- infected HL cell lines, the higher levels of Chemokine (C-C motif) ligand 20 (CCL20) in the supernatants increase the migration of $\mathrm{CD} 4^{+}$lymphocytes that express FOXP3, a marker of Tregs. Inducing the expression of CCL20 might be a mechanism by which EBV can recruit Tregs to the microenvironment of HL and, by doing so, prevent immune responses against the virus-infected tumor population [61].

The malignant Hodgkin/Reed-Sternberg (HRS) cells of classical Hodgkin lymphoma (HL) are derived from mature B cells, but have lost a considerable part of the $\mathrm{B}$ cell-specific gene expression pattern. Consequences of such a lineage infidelity for lymphoma pathogenesis are currently not defined. HRS cells aberrantly express the common cytokine-receptor gamma-chain (gamma(c)) cytokine IL-21, which is usually restricted to a subset of $\mathrm{CD}^{+}{ }^{+} \mathrm{T}$ cells, and the corresponding IL-21 receptor. IL21 activated STAT3 in HRS cells, up-regulates STAT3 target genes, and protects HRS cells from CD95 death receptor-induced apoptosis. Furthermore, IL-21 is involved in the up-regulation of CC chemokine macrophage-inflammatory protein-3 $\alpha$ (MIP-3 $\alpha)$ in HRS cells. MIP $-3 \alpha$ in turn attracts $\mathrm{CCR} 6{ }^{+} \mathrm{CD} 4{ }^{+} \mathrm{CD} 25^{+} \mathrm{FOXP} 3$ ${ }^{+} \mathrm{CD} 127^{\text {low }}$ regulatory $\mathrm{T}$ cells toward HRS cells, which might favor their immune escape. Together, these data support the concept that aberrant expression of B lineage-inappropriate genes plays an important role for the biology of HL tumor cells [62]. Thus, the Tregs in HL may serve as suppressor Tregs, and is associated with the loss of EBV-specific immunity.

\section{Tregs and tumor immunotherapy}

Tumor-induced immunotolerance mediated by inducible Treg (iTreg) is a major obstacle to tumor immunotherapy. Tregs induced by a shared idiotype epitope can systemically suppress $\mathrm{T}$ cell responses against idiotype-derived and immunodominant foreign epitopes in vivo. So tumor vaccines should avoid epitopes expressed by normal cells in the draining lymph node to achieve optimal anti-tumor efficacy [63]. In a basic study of immunotolerance, injection of an endogenous superantigen, i.e. the minor lymphocyte stimulatory (Mls)-1(a), into specific TCR Vß8.1-transgenic (Tg) mice enables generation of anergic CD25- iTreg, the immunosuppressive function of which is maintained by IL-10 production via $\mathrm{p} 38$-mitogen-activated protein kinase (MAPK) activation. Ovalbumin peptide OVA (323-339) iv. injection into its specific TCR-Tg (OT-II) mice also induces adaptive tolerance by iTreg. Peptide immunotherapy with p38-inhibitor after $\mathrm{CD}_{2} 5^{+}$Treg-depletion is performed in an OVA-expressing lymphoma $\mathrm{E}$. G7-bearing tolerant model establishes by adoptive transfer of OT-II CD25- iTreg, which results in suppression of tumor growth. Similarly, the antitumor immunity induced by peptide immunotherapy in colon carcinoma CT26-bearing mice, in which the number of IL-10secreting iTreg is increased, is augmented by treatment with p38-inhibitor after $C D 25^{+}$Treg-depletion and results in inhibition of tumor progression. These results suggest that simultaneous inhibition of two distinct Treg-functions may be important to the success of tumor immunotherapy [64]. Tregs depletion in mice leads to tumor rejection that is dependent on $\mathrm{T}$ cells, natural killer (NK) cells, and IFN- $\gamma$. In the absence of Tregs, elevated level of IFN- $\gamma$ are produced by tumorinfiltrating $\mathrm{T}$ cells and NK cells. Tumor rejection observed in the absence of Tregs correlates with a substantial IFN- $\gamma$-dependent increase in the numbers of tumor-infiltrating leukocytes. The most abundant cell populations in the tumors are macrophages. Tumorinfiltrating macrophages from Tregs-depleted mice express increased amounts of major histocompatibility complex (MHC) class II, produce highly enhanced levels of pro-inflammatory cytokines, and inhibit tumor cell proliferation. It has been reported that tumor-infiltrating macrophages have multi-faceted functions promoting or counteracting tumor growth. High numbers of macrophages infiltrating $\mathrm{MHC}$ class I-deficient tumor cell line (RMA-S) tumors in the absence of Tregs correlate with tumor rejection suggesting that macrophages are additional targets for Tregs-mediated immune suppression in cancer [65].

Since many types of lymphoma are Epstein Barr Virus (EBV) positive, there are several strategies of targeting Tregs in the immunotherapy against EBV-positive lymphoma [66]. (1) Manipulating Tregs functions by depleting Tregs or blocking its suppressive regulatory molecules may provide a novel therapeutic approach for 
EBV-positive lymphomas. (2) The EBV epitope antigens, which can activate a Th1 response but not a regulatory $\mathrm{T}$ cell type 1 ( $\operatorname{Tr} 1)$ regulatory response should be considered, and the concentration of peptides vaccine should also be carefully evaluated for the vaccination against EBV positive lymphomas. (3) Depletion of Tregs should be performed before infusion of EBV specific CTL to enhance the clinical therapeutic benefit of $\mathrm{CD} 8^{+}$ EBV-specific CTL immunotherapy. (4) Selection of suitable timepoints for infusing CTL into the patients is important to attenuate the inhibitory effect of Tregs on the EBV-specific CTL adoptive immunotherapy [67].

\section{Conclusion}

The regulatory $\mathrm{T}$ cells - Tregs - play an important role in malignant lymphomas, but much remains to be clarified. Differed from epithelial carcinomas, Tregs in lymphoma must be more complex. In patients with different types of lymphomas, the percentage of tumorinfiltrating FOXP3 ${ }^{+} \mathrm{T}$ cells predicts different survival and prognosis. Not only the percentages but also the functions of Tregs are critical. Our new classification of Tregs into four groups is significant in providing an insight into the effects of Tregs-host microenvironment interaction on Tregs' function. In addition, our new classification also predicts prognosis of the diseases and is very useful in designing Tregs-based immunotherapies for treating lymphomas in the future. Therefore, it is possible that the effect of Tregs fundamentally differs in lymphoid malignancies compared with epithelial carcinomas. Further research is needed in determining how to use Tregs as prognostic factors and therapy strategies in treating different lymphomas.

\section{Acknowledgements}

We are very grateful to Prof. Xiao-Feng Yang and Ms. Jietang Mai in Temple University School of Medicine in Philadelphia, U.S.A., for critical readings.

\section{Authors' contributions}

JW wrote the paper, XYK designed and revised the paper. All authors read and approved the final manuscript.

\section{Competing interests}

The authors declare that they have no competing interests.

Received: 16 November 2011 Accepted: 9 December 2011 Published: 9 December 2011

\section{References}

1. Mai J, Wang H, Yang XF: Th 17 cells interplay with Foxp3+ Tregs in regulation of inflammation and autoimmunity. Front Biosci 2010, 15:986-1006.

2. Sakaguchi S, Sakaguchi N, Shimizu J, Yamazaki S, Sakihama T, Itoh M, Kuniyasu Y, Nomura T, Toda M, Takahashi T: Immunologic tolerance maintained by CD25+ CD4+ regulatory T cells: their common role in controlling autoimmunity, tumor immunity, and transplantation tolerance. Immunol Rev 2001, 182:18-32.
3. Taams LS, Smith J, Rustin MH, Salmon M, Poulter LW, Akbar AN: Human anergic/suppressive CD4+CD25+ T cells: a highly differentiated and apoptosis-prone population. Eur J Immunol 2001, 31:1122-31.

4. Shevach EM: CD4+CD25+ suppressor T cells: more questions than answers. Nat Rev Immunol 2002, 2:389-400.

5. de Jong D: Molecular pathogenesis of follicular lymphoma: a cross talk of genetic and immunologic factors. J Clin Oncol 2005, 23(26):6358-63.

6. Drach J, Seidl S, Kaufmann H: Treatment of mantle cell lymphoma: targeting the microenvironment. Expert Rev Anticancer Ther 2005, 5(3):477-85.

7. Ansell SM, Stenson M, Habermann TM, et al: CD4+ T-cell immune response to large B-cell non-Hodgkin's lymphoma predicts patient outcome. J Clin Oncol 2001, 19(3):720-6.

8. Sakaguchi S: Naturally arising CD4+ regulatory T cells for immunologic self-tolerance and negative control of immune responses. Annu Rev Immunol 2004, 22:531-562

9. Ghiringhelli F, Ménard C, Terme M, Flament C, Taieb J, Chaput N, Puig PE, Novault S, Escudier B, Vivier E, Lecesne A, Robert C, Blay JY, Bernard J, Caillat-Zucman S, Freitas A, Tursz T, Wagner-Ballon O, Capron C, Vainchencker W, Martin F, Zitvogel L: CD4+CD25+ regulatory T cells inhibit natural killer cell functions in a transforming growth factor-betadependent manner. J Exp Med 2005, 202(8):1075-85.

10. Ralainirina N, Poli A, Michel T, Poos L, Andrès E, Hentges F, Zimmer J: Control of NK cell functions by CD4+CD25+ regulatory T cells. J Leukoc Biol 2007, 81(1):144-53.

11. Ghiringhelli F, Menard C, Martin F, Zitvogel L: The role of regulatory T cells in the control of natural killer cells: relevance during tumor progression. Immunol Rev 2006, 214:229-238.

12. Han S, Huang Y, Liang Y, Ho Y, Wang Y, Chang LJ: Phenotype and functional evaluation of ex vivo generated antigen-specific immune effector cells with potential for therapeutic applications. J Hematol Oncol 2009, 2:34

13. Ke X, Wang J, Li L, Chen IH, Wang H, Yang XF: Roles of CD4+CD25(high) FOXP3+ Tregs in lymphomas and tumors are complex. Front Biosci 2008, 13:3986-4001.

14. Yang XF: Factors regulating apoptosis and homeostasis of CD4+ CD25 (high) FOXP3+ regulatory T cells are new therapeutic targets. Front Biosci 2008, 13:1472-99.

15. Wu ZL, Song YQ, Shi YF, Zhu J: High nuclear expression of STAT3 is associated with unfavorable prognosis in diffuse large B-cell lymphoma. J Hematol Oncol 2011, 4(1):31.

16. Kosmaczewska A, Ciszak L, Potoczek S, Frydecka I: The significance of Treg cells in defective tumor immunity. ArchlmmunolTherExp (Warsz) 2008, 56(3):181-91.

17. Ansell SM, Stenson M, Habermann TM, Jelinek DF, Witzig TE: CD4+T cell immune responseto large B-cell nonHodgkin'slymphomapredictspatientoutcome. J Clin Oncol 2001, 19:720-726.

18. Nomura T, Sakaguchi S: Naturally arising CD25+CD4+ regulatory $T$ cells in tumor immunity. Curr Top Microbiol Immunol 2005, 293:287-302.

19. Roncador G, Garcia JF, Garcia JF, Maestre L, Lucas E, Menarguez J, Ohshima K, Nakamura S, Banham AH, Piris MA: FOXP3, a selective marker for a subset of adult T-cell leukaemia/lymphoma. Leukemia 2005, 19(12):2247-53.

20. Clark RA: Regulation gone wrong: a subset of Sézary patients have malignant regulatory T cells. J Invest Dermatol 2009, 129(12):2747-50

21. Tzankov A, Meier C, Hirschmann P, Went P, Pileri SA, Dirnhofer S: Correlation of high numbers of intratumoral FOXP3+ regulatory $T$ cells with improved survival in germinal center-like diffuse large B-cell lymphoma, follicular lymphoma and classical Hodgkin's lymphoma. Haematologica 2008, 93(2):193-200.

22. Lee NR, Song EK, Jang KY, Choi HN, Moon WS, Kwon K, Lee JH, Yim CY, Kwak JY: Prognostic impact of tumor infiltrating FOXP3 positive regulatory $\mathrm{T}$ cells in diffuse large B-cell lymphoma at diagnosis. Leuk Lymphoma 2008, 49(2):247-56.

23. Bruneau J, Canioni D, Renand A, Marafioti T, Paterson JC, Martin-Garcia N, Gaulard P, Delfau MH, Hermine O, Macintyre E, Brousse N, Asnafi V: Regulatory T-cell depletion in angioimmunoblastic T-cell lymphoma. Am J Pathol 2010, 177(2):570-4 
24. Lin H, Sun XF, Zhen ZJ, Xia Y, Ling JY, Huang HQ, Xia ZJ, Lin TY: Correlation between peripheral blood $\mathrm{CD} 4+\mathrm{CD} 25$ high $\mathrm{CD} 127$ low regulatory $\mathrm{T}$ cell and clinical characteristics of patients with non-Hodgkin's lymphoma. Ai Zheng 2009, 28(11):1186-92.

25. Mittal S, Marshall NA, Duncan L, Culligan DJ, Barker RN, Vickers MA: Local and systemic induction of CD4+CD25+ regulatory T-cell population by non-Hodgkin lymphoma. Blood 2008, 111(11):5359-70.

26. Yang ZZ, Novak AJ, Ziesmer SC, Witzig TE, Ansell SM: Attenuation of CD8 (+) T-cell functionby CD4(+)CD25(+) regulatory T cells in B-cell nonHodgkin's lymphoma. Cancer Res 2006, 66:10145-10152.

27. Hilchey SP, De A, Rimsza LM, Bankert RB, Bernstein SH: Follicular lymphoma intratumoral $\mathrm{CD} 4+\mathrm{CD} 25+\mathrm{GITR}+$ regulatory $\mathrm{T}$ cells potently suppress CD3/CD28-costimulated autologous and allogeneic CD8+CD25and CD4+CD25- T cells. J Immunol 2007, 178:4051-4061.

28. Feng LL, Gao JM, Li PP, Wang X: IL-9 Contributes to Immunosuppression Mediated by Regulatory T Cells and Mast Cells in B-Cell Non-Hodgkin's Lymphoma. J Clin Immunol 2011, 31(6):1084-94.

29. Lindqvist CA, Christiansson LH, Simonsson B, Enblad G, Olsson-Strömberg U, Loskog AS: T regulatory cells control T-cell proliferation partly by the release of soluble CD25 in patients with B-cell malignancies. Immunology 2010, 131(3):371-6

30. McDonnell TJ, Korsmeyer SJ: Progression from lymphoid hyperplasia to high-grade malignant lymphoma in mice transgenic for the $t(14 ; 18)$. Nature 1991, 349:254-256

31. Dave SS, Wright G, Tan B, Rosenwald A, Gascoyne RD, Chan WC, Fisher RI, Braziel RM, Rimsza LM, Grogan TM, Miller TP, LeBlanc M, Greiner TC, Weisenburger DD, Lynch JC, Vose J, Armitage JO, Smeland EB, Kvaloy S, Holte H, Delabie J, Connors JM, Lansdorp PM, Ouyang Q, Lister TA, Davies AJ, Norton AJ, Muller-Hermelink HK, Ott G, Campo E, Montserrat E, Wilson WH, Jaffe ES, Simon R, Yang L, Powell J, Zhao H, Goldschmidt N, Chiorazzi M, Staudt LM: Prediction of survival in follicular lymphoma based on molecular features of tumor-infiltrating immune cells. $N$ Engl J Med 2004, 351:2159-2169.

32. Walker MR, Kasprowicz DJ, Gersuk VH, Benard A, Van Landeghen M, Buckner JH, Ziegler SF: Induction of FoxP3 and acquisition of T regulatory activity by stimulated human CD4+CD25- T cells. The Journal of clinical investigation 2003, 112:1437-43.

33. Moseman EA, Liang X, Dawson AJ, Panoskaltsis-Mortari A, Krieg AM, Liu Y-J, Blazar BR, Chen W: Human Plasmacytoid Dendritic Cells Activated by CpGOligodeoxynucleotides Induce the Generation of CD4+CD25+ Regulatory T Cells. J Immunol 2004, 173:4433-42.

34. Ito $T$, Yang $M$, Wang $Y-H$, Lande $R$, Gregorio J, Perng OA, Qin X-F, Liu Y-J, Gilliet M: Plasmacytoid dendritic cells prime IL-10-producing T regulatory cells by inducible costimulator ligand. J Exp Med 2007, 204:105-15.

35. Yang Z-Z, Novak AJ, Ziesmer SC, Witzig TE, Ansell SM: CD70+ non-Hodgkin lymphoma $B$ cells induce Foxp3 expression and regulatory function in intratumoral CD4+CD25- T cells. Blood 2007, 110:537-44.

36. Ai WZ, Hou JZ, Zeiser R, Czerwinski D, Negrin RS, Levy R: Follicular lymphoma B cells induce the conversion of conventional CD4+ T cells to T-regulatory cells. Int J Cancer 2009, 124(1):239-44.

37. Carreras J, Lopez-Guillermo A, Fox BC, Colomo L, Martinez A, Roncador G, Montserrat E, Campo E, Banham AH: High numbers of tumor-infiltrating FOXP3-positive regulatory T cells are associated with improved overall survival in follicular lymphoma. Blood 2006, 108(9):2957-64.

38. Beltran BE, Morales D, Quinones P, Miranda RN, Goswami M, Castillo JJ: Peripheral T-cell Lymphoma With a Regulatory T-cell Phenotype: Report of a Nodal and an Extranodal Case From Peru. Appl Immuno histochem Mol Morphol 2011.

39. Ishida T, Ueda R: Immunopathogenesis of lymphoma: focus on CCR4. Cancer Sci 2011, 102(1):44-50.

40. Bangham CR, Toulza F: Adult T cell leukemia/lymphoma: FoxP3(+) cells and the cell-mediated immune response to HTLV-1. Adv Cancer Res 2011, 111:163-82.

41. Clark RA: Regulation gone wrong: a subset of Sézary patients have malignant regulatory T cells. J Invest Dermatol 2009, 129(12):2747-50.

42. Gjerdrum LM, Woetmann A, Odum N, Burton CM, Rossen K, Skovgaard GL, Ryder LP, Ralfkiaer E: FOXP3+ regulatory T cells in cutaneous T-cell lymphomas: association with disease stage and survival. Leukemia 2007, 21(12):2512-8
43. Knol AC, Quéreux G, Brocard A, Ballanger F, Khammari A, Nguyen JM, Dréno B: Absence of modulation of CD4+CD25 regulatory T cells in CTCL patients treated with bexarotene. ExpDermatol 2010, 19(8):e95-102.

44. Wada DA, Wilcox RA, Weenig RH, Gibson LE: Paucity of intraepidermal FoxP3-positive T cells in cutaneous T-cell lymphoma in contrast with spongiotic and lichenoid dermatitis. J CutanPathol 2010, 37(5):535-41.

45. Heid JB, Schmidt A, Oberle N, Goerdt S, Krammer PH, Suri-Payer E, Klemke CD: FOXP3+CD25- tumor cells with regulatory function in Sézary syndrome. J Invest Dermatol 2009, 129(12):2875-85.

46. Quaglino P, Comessatti A, Ponti R, Peroni A, Mola F, Fierro MT, Savoia P, Novelli M, Bernengo MG: Reciprocal modulation of circulating CD4+CD25 +bright $\mathrm{T}$ cells induced by extracorporeal photochemotherapy in cutaneous T-cell lymphoma and chronic graft-versus-host-disease patients. Int I Immunopathol Pharmacol 2009, 22(2):353-62.

47. Tiemessen MM, Mitchell TJ, Hendry L, Whittaker SJ, Taams LS, John S: Lack of suppressive CD4+CD25+FOXP3+ T cells in advanced stages of primary cutaneous T-cell lymphoma. J Invest Dermatol 2006 126(10):2217-23.

48. Krejsgaard T, Gjerdrum LM, Ralfkiaer E, Lauenborg B, Eriksen KW, Mathiesen AM, Bovin LF, Gniadecki R, Geisler C, Ryder LP, Zhang Q, Wasik MA, Odum N, Woetmann A: Malignant Tregs express low molecular splice forms of FOXP3 in Sézary syndrome. Leukemia 2008, 22(12):2230-9.

49. Chan JKC, Quintanilla-Martinez L, Ferry JA, Peh SC: Extranodal NK/T-cell lymphoma, nasal type. In WHO Classification of Tumours of Haematopoietic and Lymphoid Tissues.. 4 edition. Edited by: Swerdlow SH, Campo E, Harris NL, Jaffe ES, Pileri SA, Stein H, Thiele J, Vardiman JW. Lyon, France: IARC Press; 2008:285-288,

50. Peng RJ, Huang ZF, Zhang YL, Yuan ZY, Xia Y, Jiang WQ, Zeng YX, Li J: Circulating and tumor-infiltrating Foxp3+ regulatory $T$ cell subset in Chinese patients with extranodal NK/T cell lymphoma. Int J Biol Sci 2011, 7(7):1027-36.

51. Kim WY, Jeon YK, Kim TM, Kim JE, Kim YA, Lee SH, Kim DW, Heo DS, Kim CW: Increased quantity of tumor-infiltrating FOXP3-positive regulatory $\mathrm{T}$ cells is an independent predictor for improved clinical outcome in extranodal NK/T-cell lymphoma. Ann Oncol 2009, 20(10):1688-96.

52. Bonzheim I, Geissinger E, Tinguely M, Roth $S$, Grieb T, Reimer P, Wilhelm M, Rosenwald A, Müller-Hermelink HK, Rüdiger T: Evaluation of FoxP3 expression in peripheral T-cell lymphoma. Am J ClinPathol 2008 130(4):613-9.

53. Bruneau J, Canioni D, Renand A, Marafioti T, Paterson JC, Martin-Garcia N, Gaulard P, Delfau MH, Hermine O, Macintyre E, Brousse N, Asnafi V: Regulatory T-cell depletion in angioimmunoblastic T-cell lymphoma. Am J Pathol 2010, 177(2):570-4

54. Miyara M, Yoshioka Y, Kitoh A, Shima T, Wing K, Niwa A, Parizot C, Taflin C Heike T, Valeyre D, Mathian A, Nakahata T, Yamaguchi T, Nomura T, Ono M, Amoura Z, Gorochov G, Sakaquchi S: Functional delineation and differentiation dynamics of human CD4+ T cells expressing the FoxP3 transcription factor. Immunity 2009, 30:899-911.

55. Dorfman DM, Brown JA, Shahsafaei A, Freeman GJ: Programmed death-1 (PD-1) is a marker of germinal center-associated T cells and angioimmunoblastic T-cell lymphoma. Am J SurgPathol 2006, 30:802-810.

56. Gjerdrum LM, Woetmann A, Odum N, Hother C, Henrik-Nielsen R, Gniadecki R, Ralfkiaer E: FOXP3 positive regulatory T-cells in cutaneous and systemic CD30 positive T-cell lymphoproliferations. Eur J Haematol 2008, 80(6):483-9.

57. Kasprzycka M, Marzec M, Liu X, Zhang Q, Wasik MA: Nucleophosmin/ anaplastic lymphoma kinase (NPM/ALK) oncoprotein induces the T regulatory cell phenotype by activating STAT3. ProcNat|AcadSci USA 2006, 103:9964-9969.

58. Ishida T, Ishii T, Inagaki A, Yano H, Komatsu H, lida S, Inagaki H, Ueda R: Specific recruitment of $\mathrm{CC}$ chemokine receptor 4-positive regulatory $\mathrm{T}$ cells in Hodgkin lymphoma fosters immune privilege. Cancer Res 2006, 66(11):5716-22.

59. Kelley TW, Pohlman B, Elson P, Hsi ED: The ratio of FOXP3+ regulatory $T$ cells to granzyme B+ cytotoxic T/NK cells predicts prognosis in classical Hodgkin lymphoma and is independent of bcl-2 and MAL expression. Am J ClinPathol 2007, 128(6):958-65.

60. Schreck S, Friebel D, Buettner M, Distel L, Grabenbauer G, Young LS, Niedobitek G: Prognostic impact of tumour-infiltrating Th2 and 
regulatory T cells in classical Hodgkin lymphoma. HematolOncol 2009, 27(1):31-9.

61. Baumforth KR, Birgersdotter A, Reynolds GM, Wei W, Kapatai G, Flavell JR, Kalk E, Piper K, Lee S, Machado L, Hadley K, Sundblad A, Sjoberg J, Bjorkholm M, Porwit AA, Yap LF, Teo S, Grundy RG, Young LS, Ernberg I, Woodman CB, Murray PG: Expression of the Epstein-Barr virus-encoded Epstein-Barr virus nuclear antigen 1 in Hodgkin's lymphoma cells mediates Up-regulation of CCL20 and the migration of regulatory $T$ cells. Am J Pathol 2008, 173(1):195-204.

62. Lamprecht B, Kreher S, Anagnostopoulos I, Jöhrens K, Monteleone G,

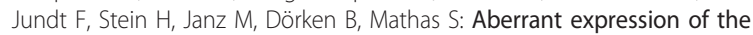
Th2 cytokine IL-21 in Hodgkin lymphoma cells regulates STAT3 signaling and attracts Treg cells via regulation of MIP-3alpha. Blood 2008, 112(8):3339-47.

63. Warncke M, Buchner M, Thaller G, Dodero A, Bulashevska A, Pfeifer D, Timmer J, Veelken H: Control of the specificity of T cell-mediated antiidiotype immunity by natural regulatory T cells. Cancer Immunol Immunother 2011, 60(1):49-60.

64. Ohkusu-Tsukada K, Toda M, Udono H, Kawakami Y, Takahashi K: Targeted inhibition of IL-10-secreting CD25- Treg via p38 MAPK suppression in cancer immunotherapy. Eur J Immunol 2010, 40(4):1011-21.

65. Galani IE, Wendel M, Stojanovic A, Jesiak M, Müller MM, Schellack C, SuriPayer E, Cerwenka A: Regulatory T cells control macrophage accumulation and activation in lymphoma. Int I Cancer 2010, 127(5):1131-40.

66. Marshall NA, Culligan DJ, Tighe J, Johnston PW, Barker RN, Vickers MA: The relationships between Epstein-Barr virus latent membrane protein 1 and regulatory T cells in Hodgkin's lymphoma. ExpHematol 2007, 35(4):596-604.

67. Li J, Qian CN, Zeng YX: Regulatory T cells and EBV associated malignancies. Int Immunopharmacol 2009, 9(5):590-2.

doi:10.1186/1756-8722-4-50

Cite this article as: Wang and Ke: The Four types of Tregs in malignant lymphomas. Journal of Hematology \& Oncology 2011 4:50.

\section{Submit your next manuscript to BioMed Central and take full advantage of:}

- Convenient online submission

- Thorough peer review

- No space constraints or color figure charges

- Immediate publication on acceptance

- Inclusion in PubMed, CAS, Scopus and Google Scholar

- Research which is freely available for redistribution

Submit your manuscript at www.biomedcentral.com/submit
Biomed Central 